\title{
Effects of rainfall variation on rice production in the Ganges-Brahmaputra Basin
}

\author{
Haruhisa Asada $^{1, *}$, Jun Matsumoto ${ }^{2}$ \\ ${ }^{1}$ Graduate School of Asian and African Area Studies, Kyoto University, Kyoto 606-8501, Japan \\ ${ }^{2}$ Department of Geography, Tokyo Metropolitan University, Hachioji, Tokyo 192-0397, Japan
}

\begin{abstract}
Rice production in India is highly correlated with monsoon rainfall. The relationships between rainfall variation and rice production have attracted significant interest at a country scale in Asia, but regional differences within a country remain unclear. In this study, we examined the effects of rainfall variation on 'kharif' rice (rainy season rice) - including temporal changes in this relationship -in the Ganges-Brahmaputra Basin, using a statistical model and a district-level data series of rice production and rainfall. Three homogeneous regions were identified within the study area. In the upper Ganges, the drought effect on rice production was dominant; however it became less pronounced due to decreased rainfall variation. In the lower Ganges, the flood effect increased due to increased rainfall. In the Brahmaputra Basin, the drought effect increased due to increased rainfall variation. Non-stationarity in the rainfall-rice production relationship was caused mainly by changes in rainfall patterns; however the impact of other factors, including social factors, should be evaluated on a regional scale.
\end{abstract}

KEY WORDS: Rice cultivation · India · Bangladesh · Ganges · Brahmaputra · Non-stationarity

\section{INTRODUCTION}

Rice is the main staple in India and Bangladesh, and these two countries account for $\sim 28 \%$ of the total rice production in the world (FAO 2008). Although total rice production in India and Bangladesh is increasing steadily every year, the weather related year-to-year variation is still large. At farm level, the price of foodgrain in India rises $>10 \%$ in the bad monsoon years (Mooley et al. 1981), and income is unstable for local farmers. Scarce rainfall even causes a drop (2 to $5 \%$ in dry monsoon years) in gross domestic product, GDP (the agricultural sector comprises $22 \%$ of GDP in India). (Gadgil 1995, Gadgil \& Rupa Kumar 2006, Gadgil et al. 2007). In addition, global warming may threaten food security in India and Bangladesh.

The impact of future climate change on agricultural production has been studied with crop simulation models (Karim et al. 1996, Kumar \& Parikh 2001, Aggarwal \& Mall 2002, Mall \& Aggarwal 2002). However, there is a potential for bias of the simulation results, depending upon the uncertainties in climate change scenarios, region of study and crop models used for impact assessment (Mall et al. 2006). Thus, it is important to understand the past links between climate and agriculture in order to improve the accuracy of crop models.

In order to reveal relationships between climate and rice cultivation, many studies have been carried out at a country scale. In India, foodgrain production, including rice production, is highly correlated with the amount of summer monsoon rainfall (SMR) from June to September (Parthasarathy et al. 1988, Parthasarathy et al. 1992, Selvaraju 2003, Krishna Kumar et al. 2004). Parthasarathy et al. (1988) found that the correlation coefficient between SMR and rice production is 0.82 (1961-1985). Parthasarathy et al. (1992) also showed that rice production can be predicted statistically by using SMR as a determinant index. El Niño-southern oscillation (ENSO) indices are also correlated with rice production in India. Krishna Kumar et al. (2004) showed that the sea-surface temperatures (SSTs) in NINO3 (SSTs averaged over $5^{\circ} \mathrm{S}$ to $5^{\circ} \mathrm{N}$ and 90 to $150^{\circ} \mathrm{W}$ ) during June to August was 
significantly correlated with total rice production in India ( $r=-0.40,1950-1998)$. Selvaraju (2003) suggested that the rice production in India could be predicted several months in advance from the SSTs in NINO3 during June to August.

However, most previous studies discuss the relationship of climate and rice production in the entire country, and it is doubtful whether the results are applicable at the state or district level. In the Indian subcontinent, rice is generally grown in the lowland of major river basins or coastal delta areas, and research at the regional scale is needed to reveal weather-yield relationships. Krishna Kumar et al. (2004) analyzed the correlation between state-level rice production and subdivisional monsoon rainfall and showed that the correlation is relatively low in some states of the eastern part of the country.

In the Ganges-Brahmaputra Basin-which ranks among monsoon Asia's most productive regions in terms of rice cultivation - the correlation between rice production and monsoon rainfall remains unknown (Krishna Kumar et al. 2004). Tanaka (1976) showed that there is a high positive correlation ( $\mathrm{r}=0.54$ for 1960-1975) between rice yield and rainfall during June to August in the Ganges Valley, but few studies have examined this area since this study. In Bangladesh, located in the lowest part of the Ganges-Brahmaputra Basin, Mowla (1976) showed that rice production and yield are highly related to fluctuations in annual rainfall. At the same time, he pointed out that the recurrent floods may also have a great influence on rice cultivation and stressed the importance of researching such a relationship.

The effect of floods on rice production in Bangladesh was investigated by many researchers. Brammer (1990) investigated the effect of severe floods in 1987 and 1988 on rice cultivation and found that transplanted aman (monsoon rice), normally planted from mid-July to mid-September, was the most affected in both years. Paul \& Rasid (1993) showed that average annual loss of rice production resulting from flooding in Bangladesh was approximately $4 \%$ of the total production, and the highest proportional loss was almost $14 \%$ in the severe flood year of 1988. Asada et al. (2005) revealed the dynamic change of the rice-cropping pattern in Bangladesh in the severe flood years of 1988 and 1998. Although the total rice production in Bangladesh is less influenced by rainfall and floods, the annual variation of rainy season rice production is still large.

Another problem is that the relationship between rainfall and rice production can change over time (i.e. it exhibits non-stationarity). For example, Parthasarathy et al. (1992) showed that the correlation coefficient for these two factors changed in different decades. The correlation coefficient between SMR and rice production in India during 1977-1988 is higher $(\mathrm{r}=$ 0.948) than for 1966-1976 ( $\mathrm{r}=0.816)$. As with other uncertainties, this uncertainty will also affect the prediction of crop models (Challinor et al. 2005a). Challinor et al. (2005b) suggested that climatic factors (such as climatic trends and random variability in the system) and nonclimatic factors (such as yield technology and changes in data accuracy) contribute to the nonstationarity of the weather-yield relationship. The non-stationarity of climate and agriculture has not been examined in depth, and it is necessary to understand these links to improve model accuracy for future yield prediction.

In the present study we investigated the effect of rainfall on rice production in both the Indian and Bangladeshi parts of the Ganges-Brahmaputra Basin over the past $40 \mathrm{yr}$, in addition to the relationship between rainfall change and rice production. Among the climatic factors affecting variation of rice production, the impact of rainfall was examined, as it is the most important limiting factor in South Asia (Gadgil \& Rupa Kumar 2006). The study was carried out for the period of 1961-2000, a period for which district-level statistics of rice production and rainfall are available.

\section{STUDY AREA}

The study area covers Bangladesh and the Indian states Assam, West Bengal (WB), Bihar and Uttar Pradesh (UP) (Fig. 1). These four states account for about $40 \%$ of the total rice production in India $(14.6,13.6,6.4$ and $4.7 \%$ in WB, UP, Bihar and Assam, respectively, in 2000/01). Assam and part of Bangladesh lie in the Brahmaputra Basin. Bihar, WB and most of Bangladesh lie in the lower Ganges Basin. UP is in the upper Ganges Basin. The study area amounts to ca. $46 \%$ of the total Ganges-Brahmaputra catchment areas $\left(1.7\right.$ million $\left.\mathrm{km}^{2}\right)$. Although the new states Uttaranchal and Jharkhand were separated out of UP and Bihar respectively in 2000, the former administrative units of UP and Bihar were considered.

The climate of the study area is predominantly a subtropical monsoon climate. In the months from June to September, the southwestern monsoon flow brings a humid air mass and causes high precipitation in the whole study area. The amount of SMR is higher in the eastern part of the basin and not so high in the western part. The onset of the summer monsoon begins in April in eastern Assam and in late May in the southeastern part of Bangladesh and advances westwards upstream of the Ganges. SMR amounts to ca. 60 to $70 \%$ of the annual rainfall and causes floods in the study area.

The rice cropping system in the study area corresponds to the local climate and hydrological environ- 


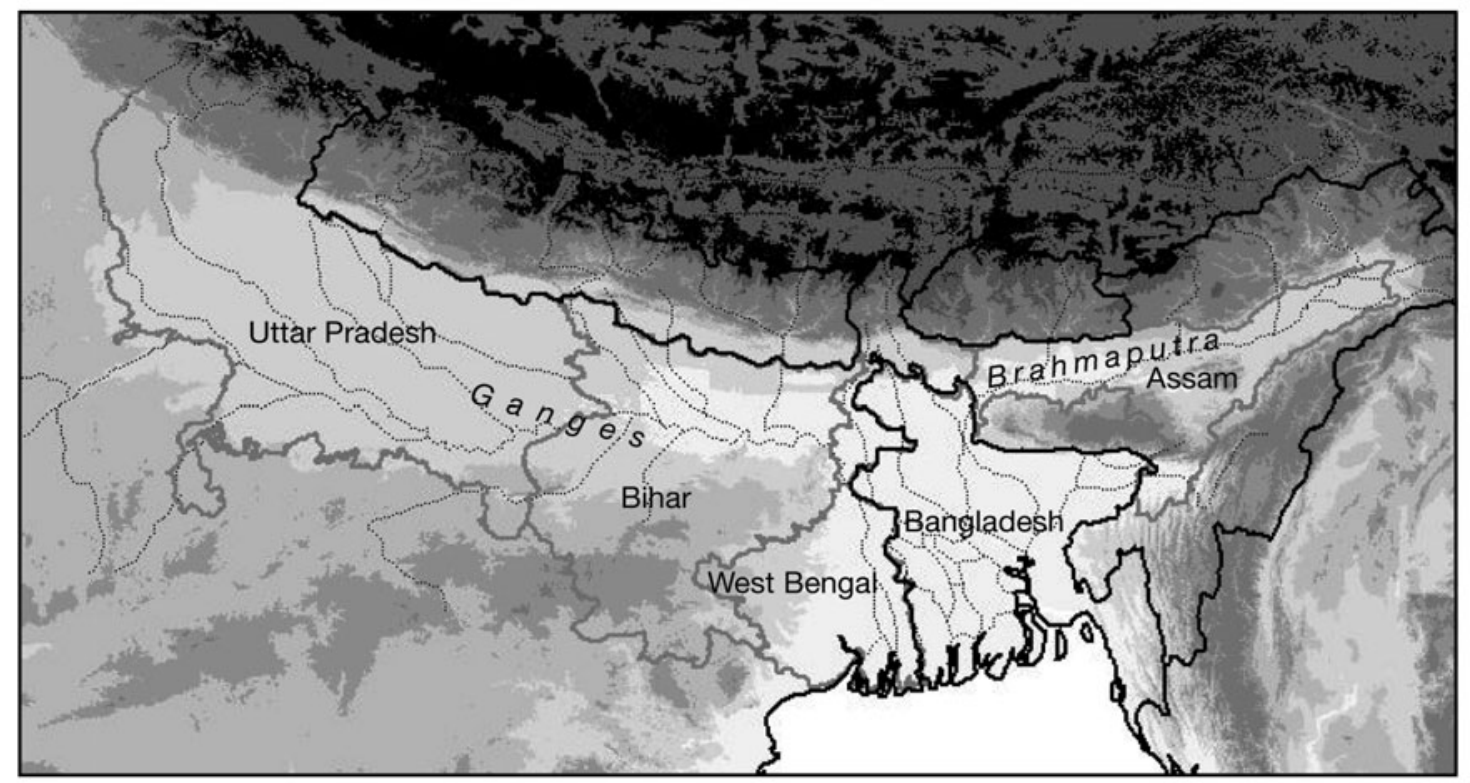

Fig. 1. Study area and the Ganges - Brahmaputra river system. The study area covered Bangladesh and 4 Indian states. Black, grey and dotted lines represent international borders, state borders and major rivers, respectively. Shading:topographical relief

ment. In Assam, Bangladesh and WB, rice is grown three times a year as follows: autumn rice (April to July), winter rice (August to November) and summer rice (December to May). Autumn and winter rice are classified as the rainy-season variety ('kharif' rice). Kharif rice is grown mostly in a rain-fed field and is more vulnerable to water shortage. In Bihar and UP, only kharif rice is grown during the year, as wheat and other crops are planted in the dry season. Summer rice is classified as the dry-season variety ('rabi' rice). Rabi rice is grown in irrigated paddy fields and yield is much higher than kharif rice owing to more hours of sunshine and fewer natural disasters than in the rainy season. As kharif rice is more vulnerable to rainfall variation than rabi rice (Krishna Kumar et al. 2004) and is cultivated throughout the study area, the effect of rainfall was only investigated on kharif rice in this study.

\section{DATA AND METHODS}

\subsection{Rice production data}

Rice production and cultivated area data at state and district level during 1961-2000 were obtained from the yearly agricultural bulletins 'Agricultural Situation in India', Dep. of Agriculture, Gov. of India, 'Yearbook of Agricultural Statistics of Bangladesh', Bangladesh Bureau of Statistics, Hamid (1991) and FAO-RAP (2008). For years where data was lacking, statistics published by local governments were used. Yield was derived by dividing production by cultivated area.

\subsection{Climate data}

Monthly rainfall data during 1961-2000 was obtained from the Indian Institute of Tropical Meteorology (IITM, www.tropmet.res.in/) and the $0.5 \times 0.5^{\circ}$ gridded dataset from the Variability Analysis of Surface Climate Observations (VASClimO) in the Global Precipitation Climatology Centre (GPCC). The details and the location of the original rain gauges of the IITM dataset are well documented in Parthasarathy et al. (1994). A brief introduction of the VASClimO dataset is reported in Beck et al. (2005). The monthly rainfall in every district was calculated from gridded data by averaging the grid value superimposed over the district area. In order to calculate the monthly value of Bangladesh rainfall, daily rainfall data at 14 stations from the Bangladesh Meteorological Department (BMD) was analyzed.

Flood-affected area data in Assam, WB, Bihar and UP during 1961-2000 were obtained from the Central Water Commission (CWC), the Ministry of Water Resources, and the Gov. of India. Flood affected area data in Bangladesh for the same period was obtained from the Flood Forecasting and Warning Center (FFWC) and the Bangladesh Water Development Board (BWDB). The assessment techniques adopted to calculate flood affected areas are reported in Mirza et al. (2001).

\subsection{Methods}

The effect of rainfall variation on rice production was investigated by statistical modeling. Simple correlation 
was examined after detrending each data series. All the time series of rainfall were normalized by their respective standard deviations (SDs) for 1961-2000. The long-term trend of technological progress in rice production, area and yield data were removed by applying the $5 \mathrm{yr}$ running mean, and the percentile anomaly from the running means were used as indices of short-term variation of production, area and yield. The flood affected ratio was derived by dividing the flood affected area by the geographical area, and the correlation with rice production was examined without detrending the time series.

The temporal correlation between rice production and SMR was examined by 7 yr moving correlation. The temporal trend of the correlation coefficient was
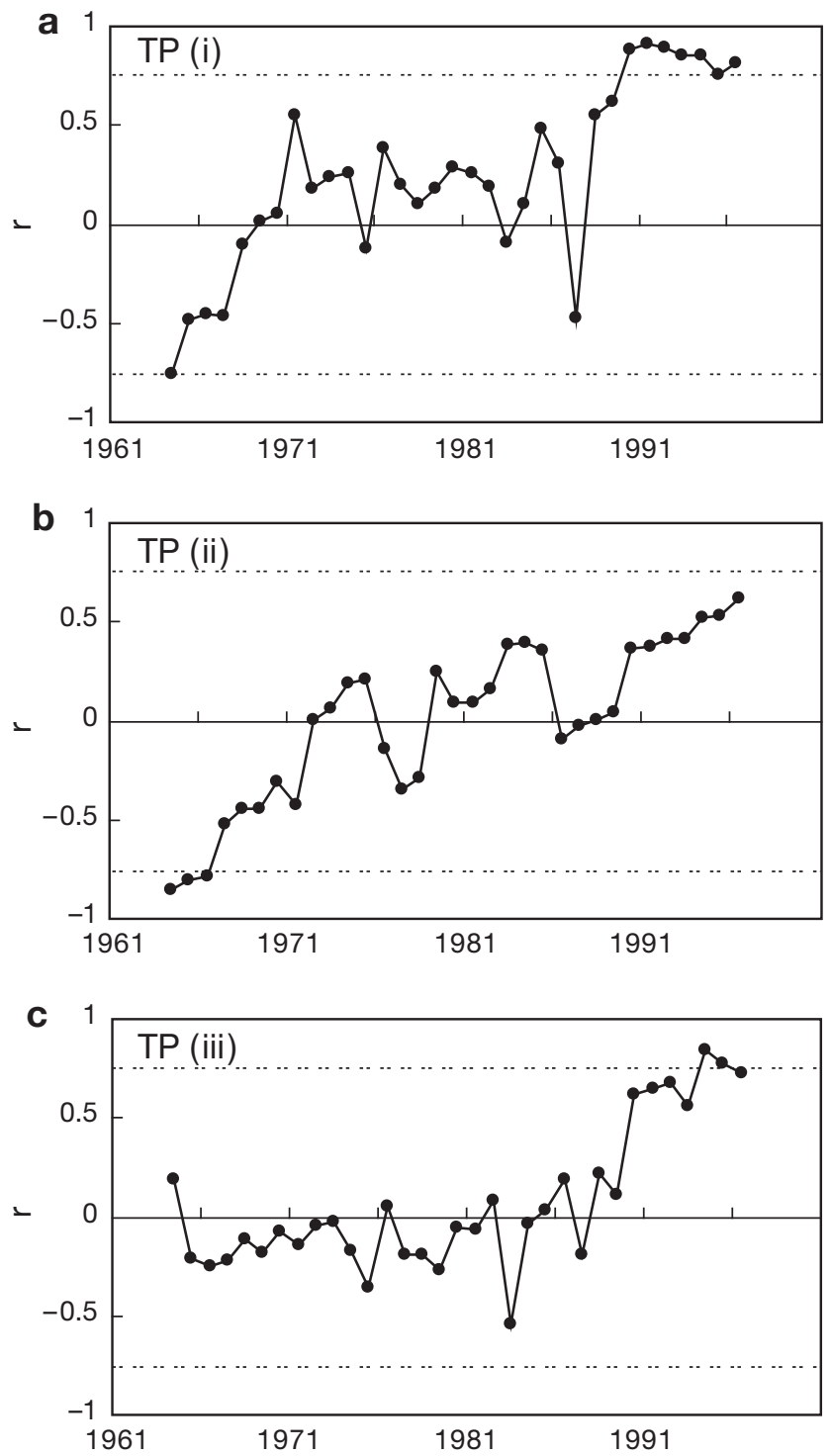

examined by Mann-Kendall rank statistics (Kendall 1938). In addition, flood effect and drought effect were examined by the significance level of the correlation coefficient $(\mathrm{r}=0.76$, significant level at $5 \%)$. Finally, the temporal change of the correlation in each district was classified into 6 classes (Fig. 2). Districts showing a significant positive trend were defined into three classes: 'flood decreasing and drought increasing' (with both positive $r$ and negative $r$, Fig. 2a), 'flood decreasing' (with only negative r, Fig. 2b) and 'drought increasing' (with only positive $r$, Fig. 2c). Districts showing a significantly negative trend were also defined into three classes: 'drought decreasing and flood increasing' (with both positive $r$ and negative $r$, Fig. 2d), 'drought decreasing' (with only positive $r$,
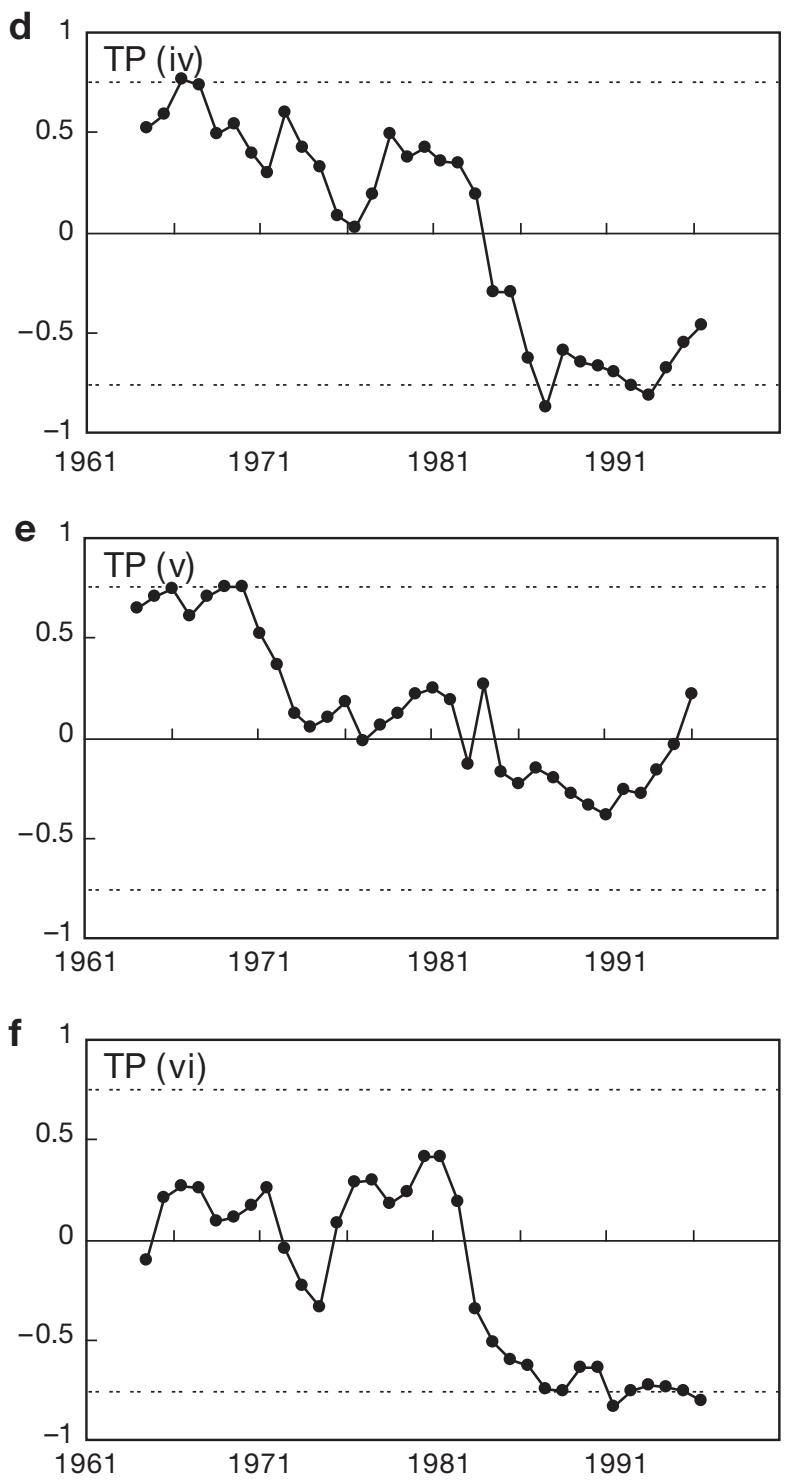

Fig. 2. Classification of district by correlation coefficient (r): (a) flood decreasing and drought increasing, (b) flood decreasing, (c) drought increasing, (d) drought decreasing and flood increasing, (e) drought decreasing, (f) flood increasing. Dotted lines: significance levels at $5 \%(\mathrm{r}=0.76)$. TP: Trend pattern (referred to in Fig. 6) 
Fig. 2e) and 'flood increasing' (with only negative r, Fig. 2f).

The trends of rainfall amount and year-to-year rainfall variations were also examined in each district. The trend of rainfall amount was examined by applying Mann-Kendall rank statistics to the 5 yr running average of rainfall time series. The trend of rainfall variations was examined by applying Mann-Kendall rank statistics to the $5 \mathrm{yr}$ running average SD of the rainfall time series.

In this study, the positive (negative) correlation between rainfall and rice production - which means that scarce (excess) rainfall causes production loss-was defined as the drought (flood) effect on rice production. Flood effect means damage caused by heavy rainfall in the area, and does not include the case of river water flooding which is caused by rainfall in upstream areas. We examined the cases when the correlation coefficient was statistically significant. But it should be noted that when the correlation coefficients were low or not significant, it does not always mean that there was not any relationship between rainfall and rice production.

\section{RESULTS}

\subsection{Rainfall effect at the state level}

Kharif rice accounts for a large fraction of total rice production in the study area (Table 1). In Bangladesh and WB (India), rabi production and area are comparatively larger. In other Indian states, rabi rice is cultivated marginally and is less important. The SDs of kharif rice in the 1990s are high, especially in Bihar, where $>10 \%$ of kharif rice production is variable every year. The variation of kharif production is largely caused by variation in yield. As the irrigated ratio in the kharif area is small, kharif rice depends on rainfall through its growing period, and yield becomes unstable. The variation of rabi rice is also large except for in Bangladesh. Yield, however, is more stable than that of kharif rice, as most of the rabi area is irrigated. Variation of rabi production is largely due to variation of cultivated area. Rabi rice is cultivated after harvest of kharif rice, and the variation in cultivated area seems to be less influenced by climatic factors.

The correlation coefficient between rainfall and kharif rice shows different characteristics of rainfall effect by state (Table 2). Rice production in Assam and
Table 2. Correlation coefficient between monthly rainfall and kharif production, area and yield for the period 1961-2000 in Bangladesh and 4 Indian states (from west to east). ${ }^{*},{ }^{* *} \mathrm{p}<$ $0.05,0.01$, respectively. Correlation with the flood-affected area also shown. WB: West Bengal; UP: Uttar Pradesh; SMR: summer monsoon rainfall

\begin{tabular}{|c|c|c|c|c|c|}
\hline & UP & Bihar & WB & Bangladesh & Assam \\
\hline \multicolumn{6}{|l|}{ Production } \\
\hline Apr & -0.02 & 0.20 & -0.05 & -0.01 & $0.40^{* *}$ \\
\hline May & -0.01 & 0.26 & 0.16 & 0.12 & 0.01 \\
\hline Jun & 0.22 & $0.31^{*}$ & $0.32^{*}$ & 0.04 & 0.12 \\
\hline Jul & $0.51^{* *}$ & $0.36^{*}$ & $0.36^{*}$ & -0.04 & 0.08 \\
\hline Aug & $0.32^{*}$ & 0.13 & 0.17 & -0.30 & -0.17 \\
\hline Sep & $0.55^{* *}$ & 0.08 & -0.05 & 0.14 & 0.15 \\
\hline SMR (JJAS) & $0.73^{* *}$ & $0.45^{* *}$ & $0.32^{*}$ & -0.10 & 0.08 \\
\hline Flood area & $0.43^{* *}$ & 0.03 & 0.03 & $-0.52^{* *}$ & -0.29 \\
\hline \multicolumn{6}{|l|}{ Area } \\
\hline Apr & -0.01 & 0.15 & 0.02 & 0.03 & 0.13 \\
\hline May & -0.02 & $0.44^{* *}$ & $0.45^{* *}$ & -0.13 & 0.00 \\
\hline Jun & $0.44^{* *}$ & 0.30 & 0.04 & -0.20 & 0.17 \\
\hline Jul & $0.56^{* *}$ & $0.57^{* *}$ & $0.39^{*}$ & -0.04 & -0.03 \\
\hline Aug & 0.16 & 0.13 & 0.16 & -0.14 & -0.16 \\
\hline Sep & 0.22 & 0.13 & -0.13 & 0.21 & -0.02 \\
\hline SMR (JJAS) & $0.62^{* *}$ & $0.58^{* *}$ & 0.17 & -0.12 & -0.01 \\
\hline Flood area & 0.29 & 0.06 & -0.16 & $-0.53^{* *}$ & -0.28 \\
\hline \multicolumn{6}{|l|}{ Yield } \\
\hline Apr & -0.02 & 0.20 & -0.06 & -0.04 & $0.46^{* *}$ \\
\hline May & 0.00 & 0.19 & 0.05 & 0.26 & 0.02 \\
\hline Jun & 0.15 & 0.28 & $0.36^{*}$ & 0.20 & 0.10 \\
\hline Jul & $0.43^{* *}$ & 0.28 & 0.30 & -0.03 & 0.10 \\
\hline Aug & $0.33^{*}$ & 0.12 & 0.15 & $-0.35^{*}$ & -0.13 \\
\hline Sep & $0.56^{* *}$ & 0.08 & 0.00 & 0.07 & 0.18 \\
\hline SMR (JJAS) & $0.68^{* *}$ & $0.38^{*}$ & $0.33^{*}$ & -0.06 & 0.13 \\
\hline Flood area & $0.41^{* *}$ & 0.01 & 0.09 & $-0.42^{* *}$ & -0.24 \\
\hline
\end{tabular}


Bangladesh has little relation to the amount of SMR. The correlation becomes higher in Bihar and UP, where the rainy season is relatively shorter and there is less SMR. Both kharif area and yield are correlated with monthly rainfall within the growing period. The correlation coefficient is significant at the $1 \%$ level in Assam (associated with April rainfall) and Bihar and UP (associated with July and September rainfall). The timing coincides with the western migration of monsoon onset, which starts in April from Assam. This is consistent with the results of Gadgil et al. (2002) that the monsoon onset has significant influence on kharif rice production. In Bangladesh, a significant negative correlation is seen between rainfall in August and kharif yield. A negative correlation is also seen in Assam, though the correlation coefficient is not significant. Rainfall in August can easily damage rice production because of flooding, as it is the peak period of river water level. The correlation coefficients between the flood affected area and kharif production, area and yield in Bangladesh and Assam all show a significant negative correlation.

\subsection{Rainfall effect at district level}

Fig. 3 shows the district-level correlation between SMR and kharif production, area and yield during 1961-2000. The positive correlation between SMR and kharif production is highest in the Gaya district of central Bihar ( $r=0.67$; $\mathrm{p}<0.01$ ), and the negative correlation is highest in the Pabna district of western Bangladesh ( $\mathrm{r}=-0.38 ; \mathrm{p}=0.02)$. The significant positive correlation is especially dominant in Bihar and UP. The number of districts showing positive correlation is largest in UP, and decreases in the order of Bihar, WB and Assam. In WB, Bangladesh and Assam, both positive and negative correlations are recognized, and a distinct pattern cannot be seen. In western Bangladesh, the negative correlation is shown in the kharif growing area. The drought effect on kharif production is mainly due to yield loss resulting from water shortage. On the other hand, the flood effect on kharif production is mainly caused from inundation of the cultivated area.
In Bangladesh, the districts along the major rivers are more vulnerable to floods.

The period and timing of rainfall as well as the total amount of SMR during the summer monsoon season is important for rice cultivation (Gadgil et al. 2002). The correlation of monthly rainfall from April to September with kharif production during 1961-2000 was investigated at the district level (Fig. 4). From April to June, during the initial stage of kharif rice production, the number of districts showing a significant correlation was relatively low compared to other periods. Rainfall from July to September shows a positive correlation

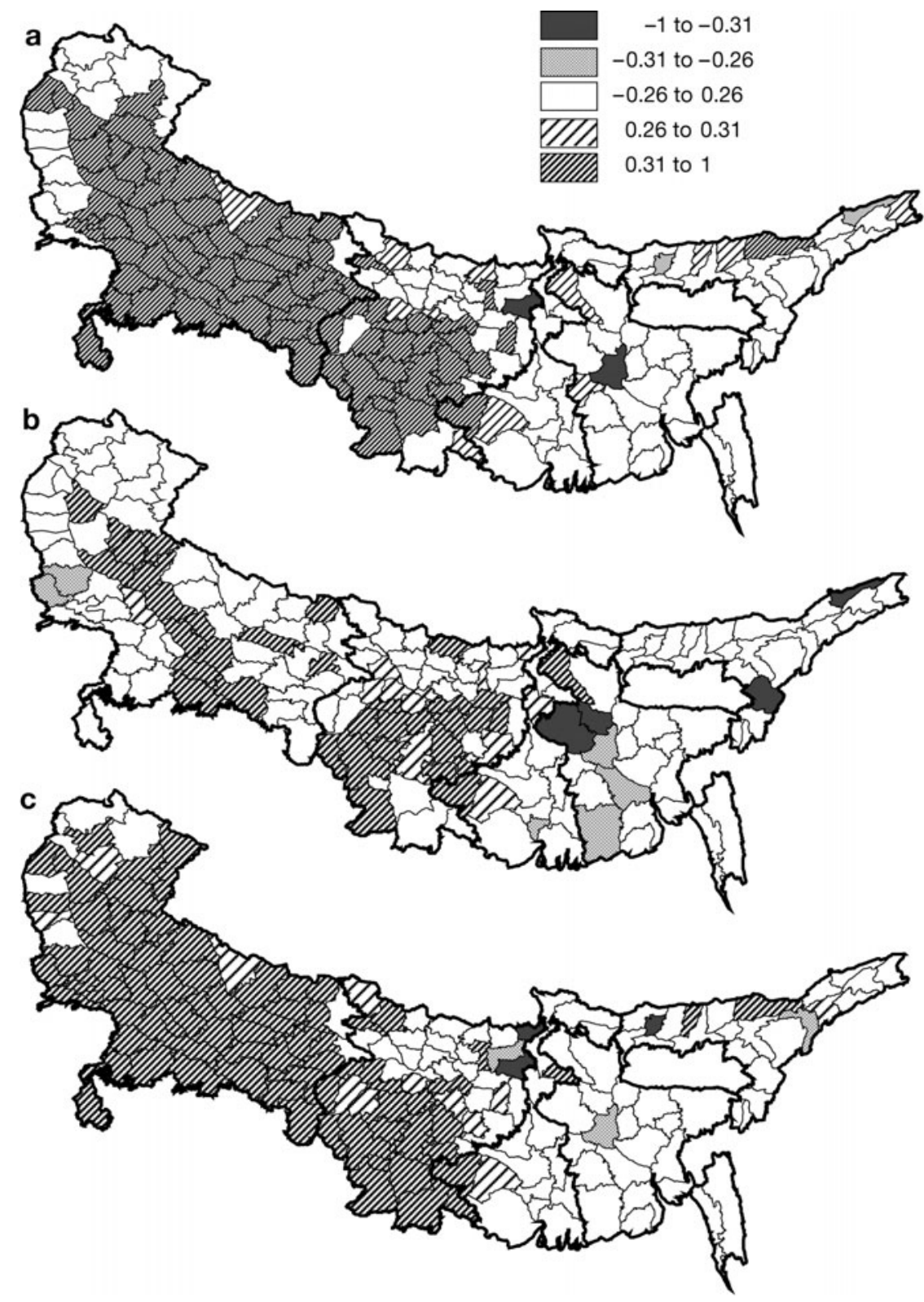

Fig. 3. Correlation coefficient between summer monsoon rainfall and kharif (a) production, (b) growing area, (c) yield for the period 1961-2000 in Bangladesh and 4 Indian states. $\mathrm{r}=0.26$ and 0.31 for significance levels of 10 and $5 \%$, respectively 

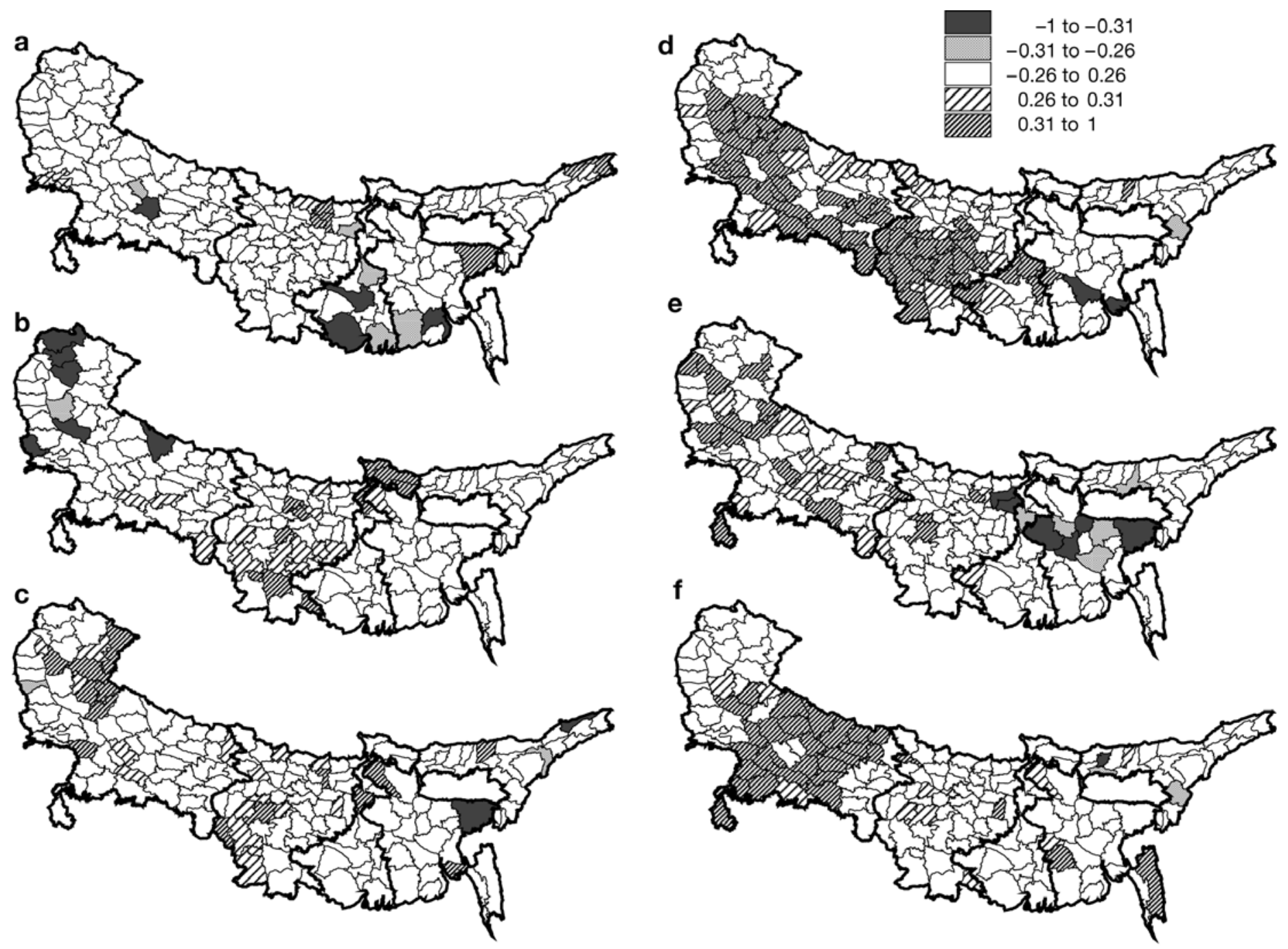

Fig. 4. Correlation coefficient between kharif production and rainfall in Bangladesh and 4 Indian states in (a) April, (b) May, (c) June, (d) July, (e) August, (f) September for the period 1961-2000. $\mathrm{r}=0.26$ and 0.31 for significance level of 10 and $5 \%$, respectively

with rice production in districts in UP and Bihar. Rainfall in August, however, is not correlated with rice production in many districts. On the contrary, a negative correlation between rice production and rainfall is seen in the wide area of the lower Ganges. In July, districts in southern Bangladesh show a negative correlation, and more districts from Bangladesh to north Bihar show a negative correlation in August. In Assam, districts with a significant correlation decreased during the whole monsoon season.

\subsection{Non-stationarity in the rainfall-rice production relationship}

The relationship between rainfall and rice production did not remain constant for the whole period. The temporal change of the correlation coefficient between
SMR and rice production in each state is shown in Fig. 5. A 7 yr moving correlation was used to examine the temporal change. There were regional differences in the temporal variation of the correlation coefficient. In UP, the correlation coefficient remained high, and exceeded the $5 \%$ significance level. In Bihar, the correlation coefficient was more variable than in UP, but remained positive over the $40 \mathrm{yr}$ period.

In Assam, Bangladesh and WB, the correlation coefficient was not constant, and the fluctuations were much larger than UP and Bihar. In Assam, the correlation coefficient was negative until 1975, but after that it turned positive, which means that the drought effect became more prominent than the flood effect. In contrast, in Bangladesh the correlation coefficient turned negative in 1975, and the flood effect increased. Similarly, the flood effect increased in WB recently, but the correlation coefficient turned negative in the early 

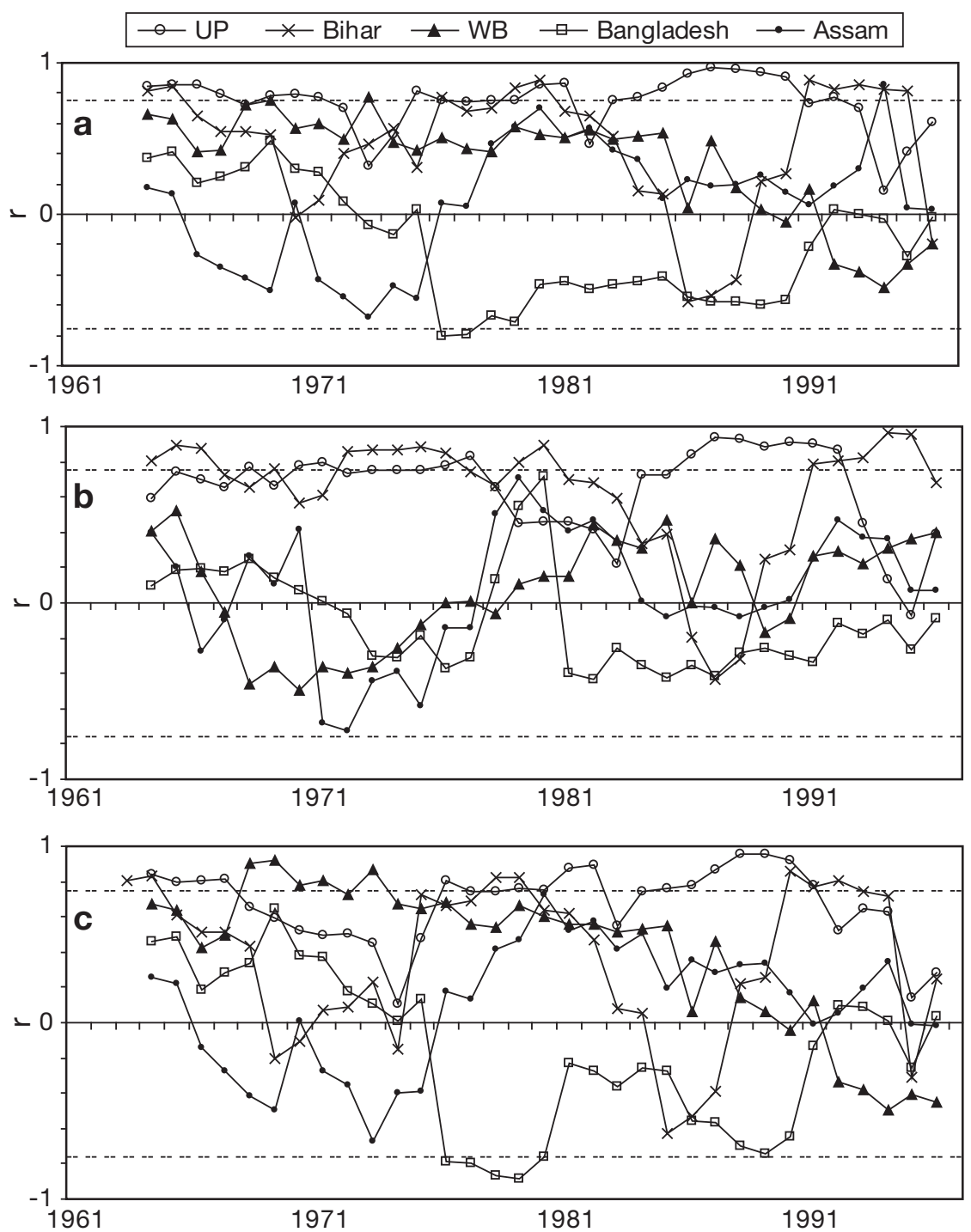

Fig. 5. Correlation coefficient between summer monsoon rainfall and kharif (a) production, (b) growing area, (c) yield in a 7 yr moving window in Bangladesh and 4 Indian states in Bangladesh and 4 Indian states. Dashed lines: significant at $5 \%$ level $(\mathrm{r}=0.76)$. WB: West Bengal; UP: Uttar Pradesh

1990s. The change in the correlation coefficient of production was largely due to the change in the correlation coefficient of yield. In Table 2, the correlation coefficient between rice production and SMR is very low in Bangladesh and Assam, and this is because the correlation coefficient changed adversely from positive to negative and vice versa over the $40 \mathrm{yr}$ period.

The investigation of temporal change of the correlation coefficient showed regional differences in nonstationarity; however, homogeneous regions can be recognized within the study area (Fig. 6). The first region includes the districts in eastern UP and southern Bihar, where the drought effect on rice production decreased. The decreasing effect of drought on yield is prominent. The second region includes the districts extending from northern Bihar to northern Bangladesh, where the flood effect on rice production increased. Some districts are adjacent to the Ganges. Both rice area and yield are influenced by an increasing flood effect. The third region includes the districts in Assam and part of northern WB, where the drought effect on rice production increased. The increasing drought effect is prominent in the districts located on the northern side of the Brahmaputra. The yield was more affected by drought than other regions. It is interesting that both northern Bihar and Assam are in the southern foothills of the Himalayas, but nevertheless had opposing rainfall trends.

The trends of rainfall amount and rainfall variation in each district are shown in Fig. 7. Three regions show distinctive changes of rainfall, and they correspond to the area showing significant nonstationarity in Fig. 6. In eastern UP and southern Bihar, variation in rainfall decreased, indicating that year-to-year variations stabilized. The SD of SMR in these districts decreased $119.6 \mathrm{~mm}$ $40 \mathrm{yr}^{-1}$ (13.7 \% of SMR) on average. Rainfall changes in April, June, August and September were responsible for the change in SMR. From north Bihar to north Bangladesh, the rainfall amount showed an increasing trend. The SMR increased $208.0 \mathrm{~mm} 40 \mathrm{yr}^{-1}(17.0 \%$ of SMR) on average, and the Malda district in central WB showed the highest rainfall increase, $324 \mathrm{~mm} 40 \mathrm{yr}^{-1}(27.7 \%$ of SMR). Rainfall changes in June, July and August are responsible. In Assam, rainfall variation increased, indicating that more extreme events like severe floods or droughts are likely to occur. The SD of rainfall increased $184.3 \mathrm{~mm}$ $40 \mathrm{yr}^{-1}$ (10.2\% of SMR). Rainfall change in May, June and September was responsible.

\section{DISCUSSION}

On the basis of the pattern of rainfall effect on rice production in the study area, 3 homogeneous regions can be identified: (1) eastern UP and southern Bihar in the upper Ganges Basin, (2) the northern part of Bihar, WB and Bangladesh in the lower Ganges Basin, and (3) northern Assam in the Brahmaputra Basin. 


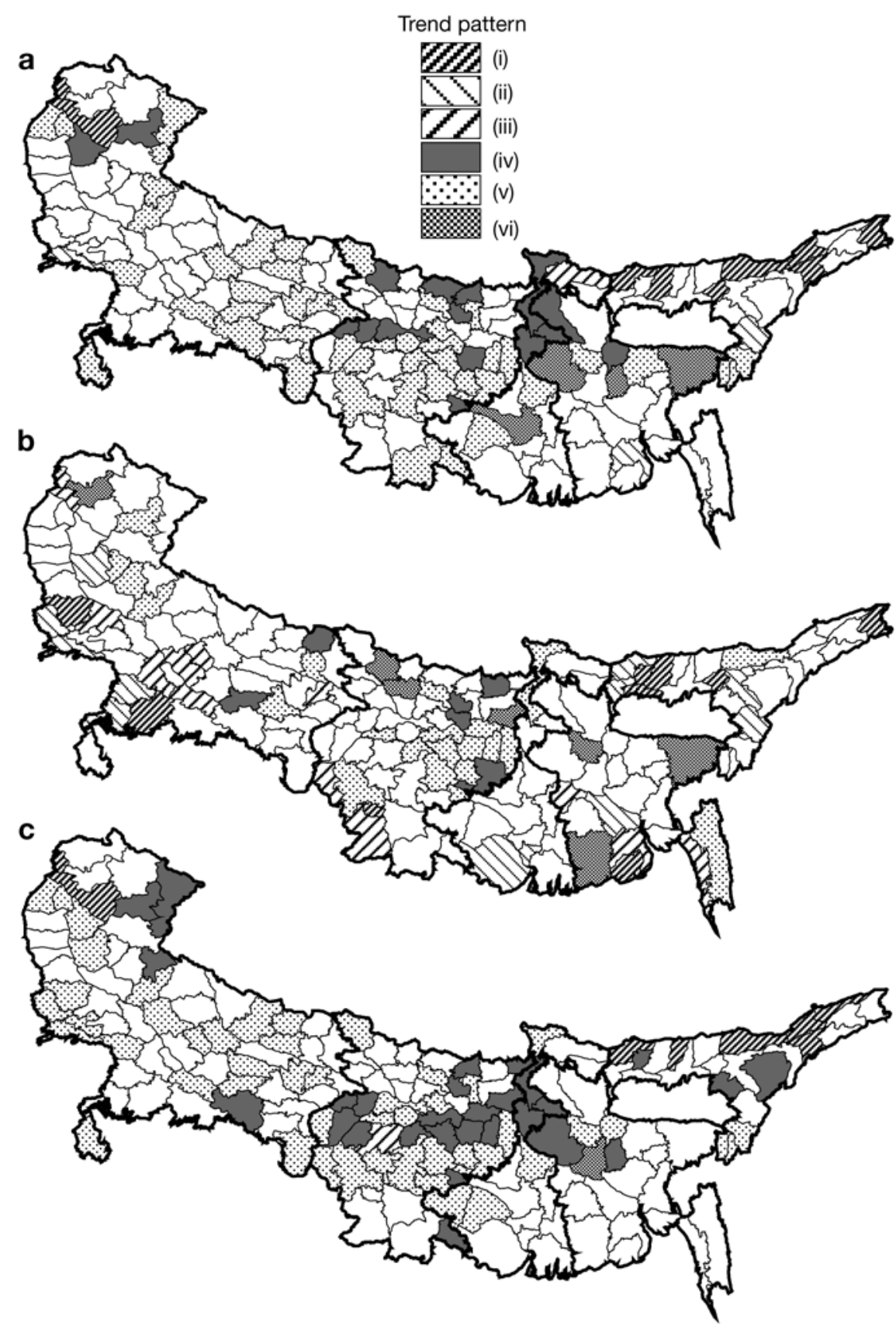

Fig. 6. Classification of district based on trend patterns (i) to (vi) (see Fig. 2). Trend of correlation coefficient between summer monsoon rainfall and kharif (a) production, (b) area, (c) yield

drought effect on rice production decreased recently. Rainfall change is favorable, as stable rainfall can decrease the drought effect and help to stabilize rice production variation.

In the lower Ganges Basin, districts along the major rivers show a flood effect on rice production, and this effect has recently been increasing. A trend of increasing rainfall may be partly responsible for the change in the relationship. Heavy rainfall in the transplanting period causes cultivated area loss, and deficiency of the growth period causes yield loss.

In the Brahmaputra Basin, district analysis shows the increasing effect of drought on rice production due to increased rainfall variation. An increase of either severe floods or droughts can cause rice production loss, but the drought effect on rice production is more prominent. At the state-level analysis, however, the correlation coefficient between the flood-affected area and rice production shows a significantly negative correlation, and thus kharif rice in Assam is vulnerable to both floods and droughts. In addition to the effect of rainwater flooding, the effect of riverwater flooding should also be used to more accurately estimate the flood effect on rice production.

All of the 3 regions are smaller than state (in India) or country (Bangladesh) level, and some extend over state borders. Analysis at state level provides insufficient resolution. It is important to analyse the rainfall-rice production relationship at a district scale, and consider this measure for amelioration of future climate changes. In the regions where the rainfall effect is increasing, measures to control the local hydrological environment such as irri-

In the upper Ganges Basin, rice production is strongly affected by rainfall fluctuation, and is vulnerable to rainfall shortage, which is similar to the relationship throughout all of India as revealed in previous studies (Parthasarathy et al. 1988, 1992, Selvaraju 2003, Krishna Kumar et al. 2004). The period of the rainy season is shorter, and the rainfall amount available for rice cultivation is limited. The scarce rainfall from July to September caused the yield loss, but the gation and the construction of flood embankments may be required. The results could also contribute towards improving the accuracy of crop models, if the local mechanism of the relationship is revealed.

Changes in the relationship between rainfall and rice production were detected over a period of $40 \mathrm{yr}$. The non-stationarity could be partly due to the rainfall change in the same period, but the mechanism still remains unclear. Flood effect increased both in Bang- 


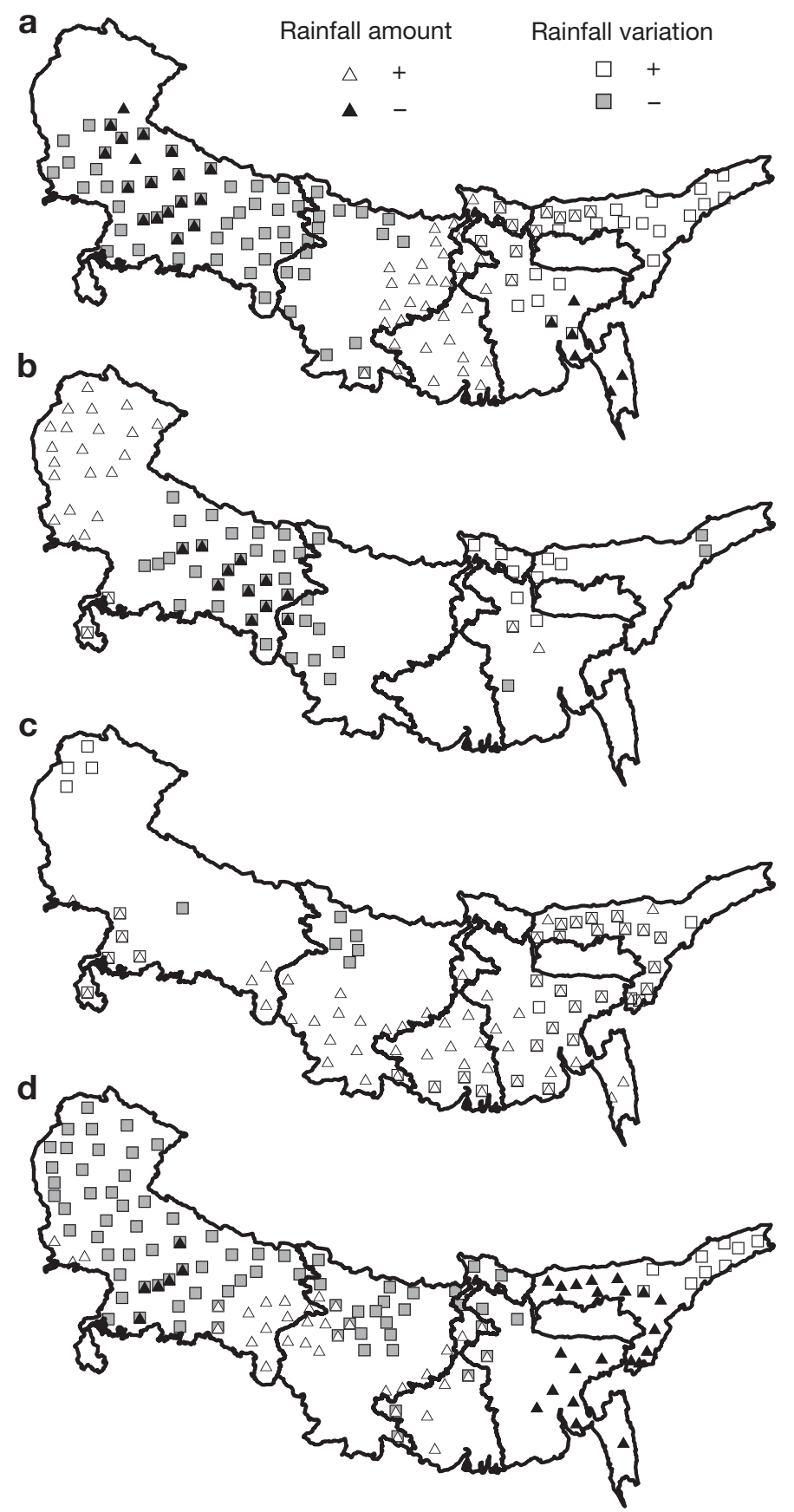

ladesh and $\mathrm{WB}$, but the timing of the prominence of the effect differed by region. Challinor et al. (2005b) suggested that social factors also contribute to nonstationarity along with climate factors. Different social factors such as introduction of irrigation or changes in cropping systems may have contributed to the different timing of temporal change.

Non-stationarity in monsoon rainfall is another important problem. SMR in the Ganges-Brahmaputra Basin showed a decreasing trend over the last century (Gregory 1989, Rupa Kumar et al. 1992). SMR in the

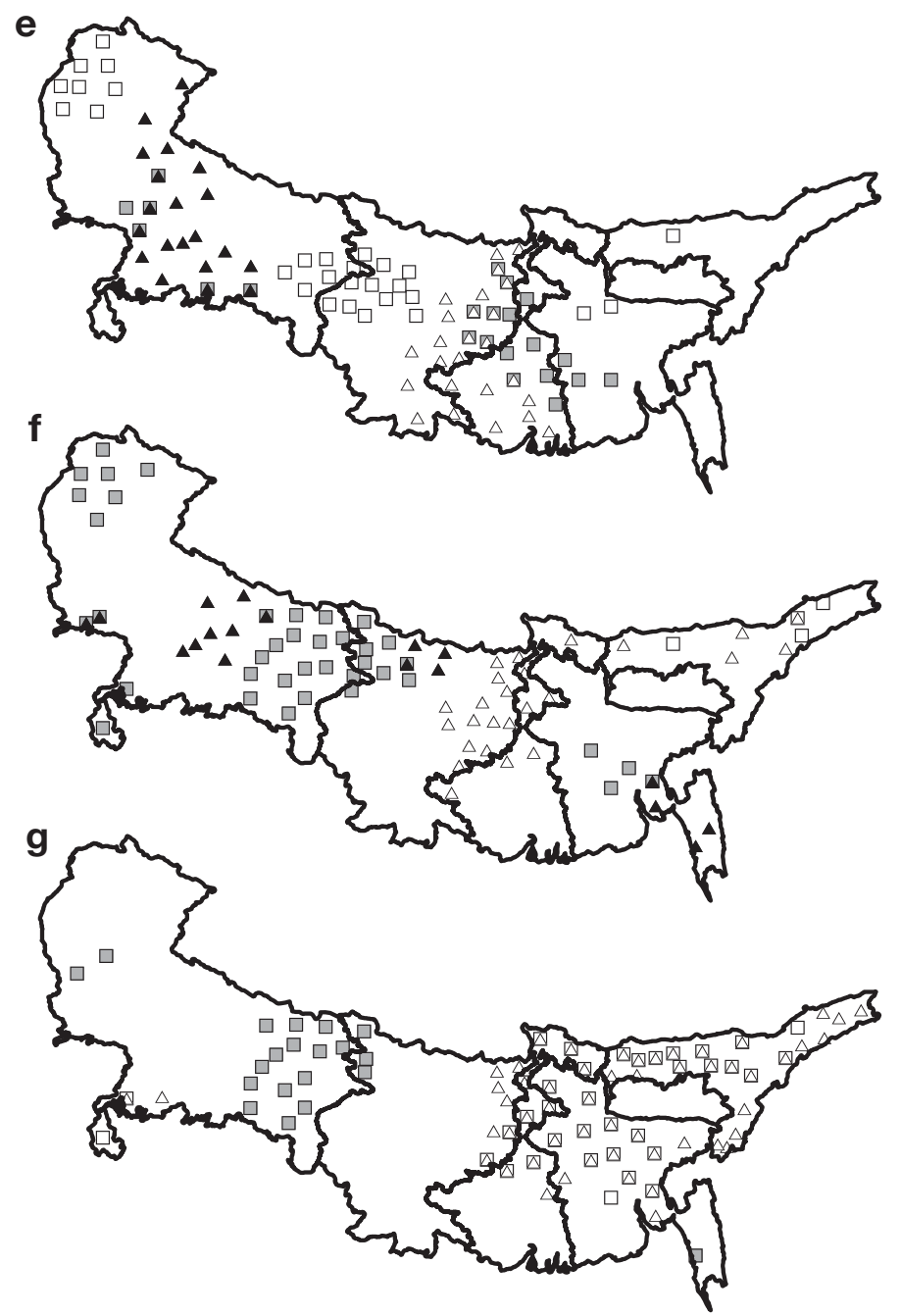

Fig. 7. Trends of rainfall amount and rainfall variation in Bangladesh and 4 Indian states for the period 1961-2000. (a) Summer monsoon rainfall, (b) April, (c) May, (d) June, (e) July, (f) August, (g) September. + (-): increasing (decreasing) trend. Significance level is at $5 \%$

eastern Ganges plain (Bihar and WB) showed a decreasing trend from 1900-1984, but began to increase after 1984 (Singh \& Sontakke 2002). The number of extreme rainfall events also showed a decreasing trend in the Ganges Basin. Extreme rainfall events of 1 to 3 d duration showed a significant decreasing trend $(>10 \%)$ in Bihar during 1901-1980 (Rakhecha \& Soman 1994), and extreme daily rainfall showed a decreasing trend in Bihar and WB during 1910-2000 (Roy \& Balling 2004). Rainfall changes in this study period are not consistent with the results of the previ- 
ous studies, and illustrate the interdecadal variation of Indian SMR (ISMR) (Parthasarathy et al. 1991). ISMR has a long-term oscillation within a period of about 30 yr (Parthasarathy et al. 1991, Krishnamurthy \& Goswami 2000), and rainfall changes for the study period in this study can be considered as a part of the cycle. The teleconnection between ISMR and ENSO changes at a decadal scale, and contributes to the interdecadal variations of ISMR (Krishnamurthy \& Goswami 2000). Turner et al. (2007) showed that the teleconnection between ISMR and ENSO is likely to remain robust with future climate change. If interdecadal variations of rainfall can be predicted on a time scale of 30 to $40 \mathrm{yr}$, it could help improve future prediction of rice production.

\section{CONCLUSIONS}

This study revealed the non-stationary effect of rainfall variation on rice cultivation in the Ganges-Brahmaputra Basin, one of the most populated and most important rice producing areas in South Asia. The majority of previous studies have analyzed the relationship between rainfall and rice production at whole country or state level. The district-level analysis used in this study more effectively revealed the area (i.e. across several districts, both interstate and intercountry) where rice production is particularly vulnerable to rainfall variation. We also found that the effect of rainfall variation on rice production changes over time in the study area, and that this non-stationarity can be explained by long-term rainfall change. However, the mechanism causing this change remains unclear, and there are still many uncertainties in the nonstationarity of the rainfall-rice production relationship.

This study provides basic information for understanding the rainfall-rice production relationship in the Ganges-Brahmaputra Basin. The effect of rainfall on rice production differs by region, so research should be carried out at a regional scale, and local mechanisms (including social factors) need to be analysed to help stabilize year to year variation of rice production. Regional planning measures - including for irrigation and river-embankment work - are necessary to minimize the influence of future rainfall change on rice cultivation. The regional and temporal scales of the nonstationarity revealed in this study should help reduce uncertainty for simulations of future climate impacts on rice production. The mechanism of non-stationarity needs to be further studied to improve the predictive accuracy of crop models.

Acknowledgements. The authors thank Prof. K. Ando, Center for Southeast Asian Studies, Kyoto University, and Prof. A. K.
Bhagabati, Department of Geography, Gauhati University, for providing helpful advice. Comments from anonymous reviewers were also appreciated. This research was supported by the Japan Society for the Promotion of Science.

\section{LITERATURE CITED}

Aggarwal PK, Mall RK (2002) Climate change and rice yields in diverse agro-environments of India. II. Effect of uncertainties in scenarios and crop models on impact assessment. Clim Change 52:331-343

Asada H, Matsumoto J, Rahman R (2005) Impact of recent severe floods on rice production in Bangladesh. Geogr Rev Jpn 78:783-793

Beck C, Grieser J, Rudolf B (2005) A new monthly precipitation climatology for the global land areas for the period 1951 to 2000. In: Climate Status Report, 2004. German Meteorological Service, Offenbach, p181-190

> Brammer H (1990) Floods in Bangladesh. I. Geographical background to the 1987 and 1988 floods. Geogr J 156: $12-22$

> Challinor AJ, Wheeler TR, Slingo JM, Hemming D (2005a) Quantification of physical and biological uncertainty in the simulation of the yield of a tropical crop using presentday and doubled CO2 climates. Philos Trans R Soc B 360: 2085-2094

Challinor AJ, Wheeler TR, Slingo JM, Craufurd PQ, Grimes DIF (2005b) Simulation of crop yields using ERA-40: limits to skill and nonstationarity in weather-yield relationships. J Appl Meteorol 44:516-531

FAO (2008) Statistical databases \& data-sets. www.fao.org/ waicent/portal/statistics_en.asp (accessed 1 October 2008)

FAO-RAP (2008) Regional data exchange system. www.faorapapcas.org/india/index.htm (accessed 1 October 2008)

Gadgil S (1995) Climate change and agriculture: an Indian perspective. Curr Sci 69:649-659

Gadgil S, Rupa Kumar K (2006) The Asian monsoon, agriculture and economy. In: Wang B (ed) The Asian monsoon. Springer, Berlin, p 651-683

Gadgil S, Seshagiri Rao PR, Rao KN (2002) Use of climate information for farm-level decision making: rainfed groundnut in southern India. Agric Syst 74:431-457

Gadgil S, Rajeevan M, Francis PA (2007) Monsoon variability: links to major oscillations over the equatorial Pacific and Indian oceans. Curr Sci 93:182-194

Gregory S (1989) Macro-regional definition and characteristics of Indian summer monsoon rainfall, 1871-1985. Int J Climatol 9:465-483

Hamid HA (1991) A database on agricultural and foodgrains in Bangladesh. Binimoy Printers, Dhaka

Karim Z, Hussain SG, Ahmed M (1996) Assessing impacts of climatic variations on foodgrain production in Bangladesh. Water Air Soil Pollut 92:53-62

Kendall MG (1938) A new measure of rank correlation. Biometrika 30:81-93

Krishna Kumar K, Rupa Kumar K, Ashrit RG, Desphpande NR, Hansen JW (2004) Climate impacts on Indian agriculture. Int J Climatol 24:1375-1393

Krishnamurthy V, Goswami BN (2000) Indian monsoonENSO relationship on interdecadal timescale. J Clim 13: 579-595

Kumar KSK, Parikh J (2001) Indian agriculture and climate sensitivity. Global Environ Change 11:147-154

Mall RK, Aggarwal PK (2002) Climate change and rice yields in diverse agro-environments of India. I. Evaluation of impact assessment models. Clim Change 52:315-330 
Mall RK, Singh R, Gupta A, Srinivasan G, Rathore LS (2006) Impact of climate change on Indian agriculture: a review. Clim Change 78:445-478

Mirza MMQ, Warrick RA, Ericksen NJ, Kenny GJ (2001) Are floods getting worse in the Ganges, Brahmaputra and Meghna basins? Environ Hazard 3:37-48

Mooley DA, Parthasarathy B, Sontakke NA, Munot AA (1981) Annual rain water over India, its variability and impact on the economy. J Clim 1:167-186

Mowla KG (1976) Relation between climatic fluctuation and rice production in Bangladesh. In: Takahashi $\mathrm{K}$, Yoshino MM (eds) Climatic change and food production. University of Tokyo Press, Tokyo, p 137-146

Parthasarathy B, Munot AA, Kothawale DR (1988) Regression model for estimation of Indian foodgrain production from summer monsoon rainfall. Agric Meteorol 42:167-182

Parthasarathy B, Rupa Kumar K, Munot AA (1991) Evidence of secular variations in Indian monsoon rainfall-circulation relationships. J Clim 4:927-938

Parthasarathy B, Rupa Kumar K, Munot AA (1992) Forecast of rainy-season foodgrain production based on monsoon rainfall. Indian J Agric Sci 62:1-8

Parthasarathy B, Munot AA, Kothawale DR (1994) All-India monthly and seasonal rainfall series 1871-1993. Theor

Editorial responsibility: Mikhail Semenov,

Harpenden, UK
Appl Climatol 49:217-224

Paul BK, Rasid H (1993) Flood damage to rice crop in Bangladesh. Geogr Rev 83:150-159

Rakhecha PR, Soman MK (1994) Trends in the annual extreme rainfall events of 1 to 3 days duration over India. Theor Appl Climatol 48:227-237

Roy SS, Balling JRC (2004) Trends in extreme daily precipitation indices in India. Int J Climatol 24:457-466

> Rupa Kumar K, Pant GB, Parthasarathy B, Sontakke NA (1992) Spatial and subseasonal patterns of the long-term trend of Indian summer monsoon rainfall. Int $\mathrm{J}$ Climatol 12:257-268

> Selvaraju R (2003) Impact of El Nino-Southern Oscillation on Indian foodgrain production. Int J Climatol 23:187-206

Singh N, Sontakke NA (2002) On climatic fluctuations and environmental changes of the Indo-Gangetic plains, India. Clim Change 52:287-313

Tanaka M (1976) Synoptic study on the recent climatic change in Monsoon Asia and its influence on agricultural production. University of Tokyo Press, Tokyo, p 81-100

Turner AG, Innes PM, Slingo JM (2007) The effect of doubled $\mathrm{CO} 2$ and model basic satte biases on the monsoon-ENSO system. I. Mean response and interannual variability. Q J R Meteorol Soc 133:1143-1157

Submitted: July 27, 2007; Accepted: December 2, 2008 Proofs received from author(s): March 30, 2009 